\title{
The role of diet in maintaining healthy skin
}

\begin{abstract}
Introduction: Skin is of crucial importance in the human system. There are numerous factors that affect its appearance and function. Various skin conditions and fast aging are manifestation of certain disturbances.
\end{abstract}

\begin{abstract}
Aim: To give information to dermatologists and nutritionists about the role of the diet in maintaining healthy skin and the usage of knowledge in everyday practice and working with patients, a detailed analysis of available literature is performed on the impact and mechanisms of various food ingredients on the role and appearance of skin. The data will be useful to the readers of this text.

Data: The data on the nutrients that affect healthy skin are obtained: The quality, health and beauty of the skin are affected by various vitamins, minerals, proteins, as well as by other nutrients. Some foods make skin shiny and healthy, but there is also bad diet for skin, as well as foods with harmful effects, depending on skin type.

Discussion: It is of crutial importance to protect skin from negative factors. In order to provide for normal functioning of the skin it is necessary to incorporate various foods of animal or plant origin, taking in consideration skin type as well.

Conclusion: It is clear why full attention should be paid to skin, its health, functions and appearance. Adequate diet is of crutial importance, with appropriate use of vitamins, minerals, proteins and other nutrients paying attention to possible benefitial effects of certain foods, adjusted to the skin type. This should be applied in everyday practice in working with patients.
\end{abstract}

Keywords: diet \& skin, vitamins, minerals, nutrients, skin type
Volume 2 Issue 6 - 2018

\author{
Mirjana Paravina \\ The University of Nis, Medical Faculty Nis, Serbia
}

Correspondence: Prof Dr. Mirjana Paravina, The University of Nis, Nis, Serbia, Tel 003816420098 04, Emailmirjanaparevina@gmail.com

Received: July 30, 2018 | Published: November 26, 2018

\section{Introduction}

Skin is the organ of crucial importance due to its numerous functions: barrier function, mechanical, immune, sensory, endocrine, thermoregulatory, vitamin D synthesis. It is involved in the respiration; it affects social and sexual communication. ${ }^{1,2}$ It is of crucial importance how skin appears to be, what depends on its texture, colour, surface, elasticity, sweating, sebum, scent. This primarily affects personal feeling as well as the reactions of other people. Factors that affect skin appearance and its function are numerous First of all, exposure to strong ultraviolet radiation should be avoided as well as smoking and staying in space filled with cigarette smoke $^{3,4}$ and also stress should be avoided. That is because free radicals are released as they destroy molecules and damage skin tissue, what brings about the loss of water and collagen deterioration as well as faster skin aging. The consequences are skin redness and dryness, loss of elasticity and wrinkling. There are opinions that genetics affects aging in only $20 \%$. Other factors make for $80 \%$ : sun exposure, smoking, especially diet, which is most important.

Adequate and balanced diet, comprised of variety of foods is extremely important. Skin mirrors processes in the whole system, so that many skin disorders and rapid aging are manifestations of certain disturbances, like lack of nutrients, vitamins and minerals. To keep your skin healthy, eat a well-balanced diet that includes plenty of protein foods, fruits and vegetables (fresh if possible) and liquids. If we "feed" skin from the inside, we can't make a mistake. Also, physical activity plays an important part.
In the aim to give information to dermatologists and nutritionists about the role of the diet in maintaining healthy skin and the usage of knowledge in everyday practice and working with patients, a detailed analysis of available literature is performed on the impact and mechanisms of various foods ingredients on the role and appearance of skin with beneficial effects, and what foods should be avoided, what diet is compatible with the particular skin type. The data will be useful to the readers of this text.

The data on the nutrients that affect healthy skin are obtained: The quality, health and beauty of the skin are affected by various vitamins (vitamin C, E, A, K, D and B complex), minerals (selenium, copper, zinc, proteins, as well as other nutrients. There is also alpha liposoic acid, dymetilaminoethanol (DMAE), hyaluronic acid, essential fatty acids. Sufficient intake of liquids is necessary with balanced healthy diet.

\section{Vitamins}

\section{Vitamin C}

Due to the sun exposure, free radicals are released, which damage collagen and elastin, fibers that sustain skin structure and make it firm and tight. The consequences are wrinkling, stains, pre-cancers and other signs of aging. ${ }^{5}$ Vitamin $\mathrm{C}$ is a potent antioxidant, ${ }^{6,7}$ which affects free radicals and diminishes their negative effects. Strengthening the immune system, it improves acne inflammation. Many other studies have found that vitamin $\mathrm{C}$ can increase collagen production, protect against damage from UVA and UVB rays, correct 
pigmentation problems, and improve inflammatory skin conditions. ${ }^{8}$ Vitamin $\mathrm{C}$ is found in citrus fruits (lemons, oranges, and grapefruit) and in other fruits (strawberries), vegetables (peppers, broccoli, cabbage, cauliflower. ${ }^{9}$ Supplements of 500 to $1000 \mathrm{mg}$ can be taken daily. Topical application can reduce the sun exposure effects.

\section{Vitamin E}

Vitamin $\mathrm{E}$ is considered to be the most important lipido-soluble antioxidant in tissues. ${ }^{10}$ Vitamin $\mathrm{E}$ is also a potent antioxidant in reduction of sun exposure damage and carcinogenic damage. ${ }^{11,12}$ If used together with vitamin A, there is lower risk of basocellular carcinoma for $70 \%$. It also reduces wrinkling. Vitamin $\mathrm{E}$ can be found in vegetable oils, nuts, seeds, olives, spinach. Supplementation of 400IU daily is recommended, with caution because of possible hemmorrhaging.

\section{Vitamin A}

Vitamin A is necessary for skin tissue regeneration. In its absence, skin becomes dry, rough and peeling. Sufficient vitamin A intake is provided through diet, so that there is no need for supplementation. Topically applied, it reduces wrinkles and skin lines - it is used as antiaging substance. It can be found in fruits and vegetables in the form of beta-carroten, which is metabolized in vitamin A in the system.

\section{Vitamin K}

It is very important for stopping hemorrhaging. It affects less bruising and dark circles around eyes.

\section{Vitamin B complex}

From this group, the most important one for skin is biotin (B7) which is the skin, nales and hair foundation. If there is lack of this vitamin, skin inflammation followed by itching and peeling, with possible hair loss may occur. It can be found in bananas, eggs and rice. Niacin (B3) maintains skin moisturized and has anti-inflammatory effects. It can be synthesized in the system, and it occurs in many foods (meat, fish, milk, leafy vegetables, cereals, legumes). Panthoteic acid (B5) has positive effects on damaged and dry skin. It can be found in milk, yeast, liver and kidneys, seeds, broccoli.

\section{Minerals that improve the skin appearance and its quality}

\section{Selenium}

Selenium protects skin from the sun exposure damage and plays a key role in elastin development, which is important for the skin structure. It can be found in sea food, whole wheat, nuts, eggs, garlic.

\section{Copper}

Copper and zink enable elastin development. The lack of copper is rarely registered. Oral intake or in the form of cremes lower fat production. It is efficient in acne treatment and in prevention of the appearance of the new ones. It is found in poultry, red meat, and oysters.

\section{Zinc}

Zinc is an important trace mineral that aids repair of damaged tissue and heals wounds. Another important application of zink includes protecting skin from the sun's harmful ultraviolet rays. Food sources high in zink include: oysters, pecans, poultry, pumpkin seeds, ginger, legumes, sea food, mushrooms and whole grains.

\section{Alpha-lipoic acids}

They are strong antioxidants, protecting cells from damage that free radicals cause- free radical neutralizer, ${ }^{13}$ while also slow down the skin aging process. They can be used as supplements or in the form of cream. DMAE also has effects like an antioxidant. It enables cell membrane stabilization, soothing the sun exposure damage as well as pollution provoked damage. It also prevents lipofuscin creation, the pigment responsible for the creation of dark areas on the skin. It is used as the addition for mesotherapy as well as in creams.

\section{Hyaluronic acid}

This is a component of every living organism and an intercellular substance, which lubricates joints as well as it, affects cells as a type of glue, holding them together and making skin smooth and full. Hyaluronic acid is powerful antioxidant within the skin that prevents wrinkle-producing free radical damage of the skin as well as maintain the normal level of hydration within the skin. ${ }^{14} \mathrm{I}$ is not present in natural diet, so that it is supplemented locally (hyaluron fillers, creams).

\section{Essential fatty acids}

Omega-3 fatty acids and omega- 6 fatty acids are a valuable nutrient for the skin. ${ }^{15}$ They play two major roles in the body: provide appropriate structure, flexibility and functioning of cell membranes and are essential for the synthesis of intracellular lipids in stratum corneum. Being the precursor of eicosanoids (prostoglandins, leukotrienes, thromboxynes), they also have regulatory properties. ${ }^{16}$ They are very important in the fat production which makes for a natural skin barrier. In case they are lacking, skin becomes dry and easily inflamed, due to the presence of other irritating fats produced in skin. ${ }^{17}$ Omega-3 fatty acids also have anti-inflammatory properties, aiding acne and face redness reduction. Diet provides sufficient intake (wheat, poultry, oils, pastry), while omega-3 fatty acids (which are abundant in cold water fish - salmon, mackerel, sardines) have to be supplemented in the form of fish oil. They make skin looks younger and smoother. With balanced diet and occasional multivitamin supplementation, sufficient intake of liquids and skin care are necessary.

\section{Foods that make skin shiny and healthy ${ }^{18}$}

i. Carrots (beta carotene - vitamin A)

ii. Green tea (anti-oxidants- lower stress, good sleep)

iii. Citrus fruits (Vitamin C)

iv. Berries

v. Tomato (antioxidant)

vi. Almonds, walnuts (healthy fats - energy for exercise and functioning of the system)

vii. Unsweetened yoghurt (good for teeth, bones better digestion)

viii. Cheese (prevention of gums and cavity problems- oral bacteria)

ix. Vegetables (minerals, vitamins, fibers, low calories - reduced bloating, shiny young appearing skin)

x. Sweet potato (antioxidant) 


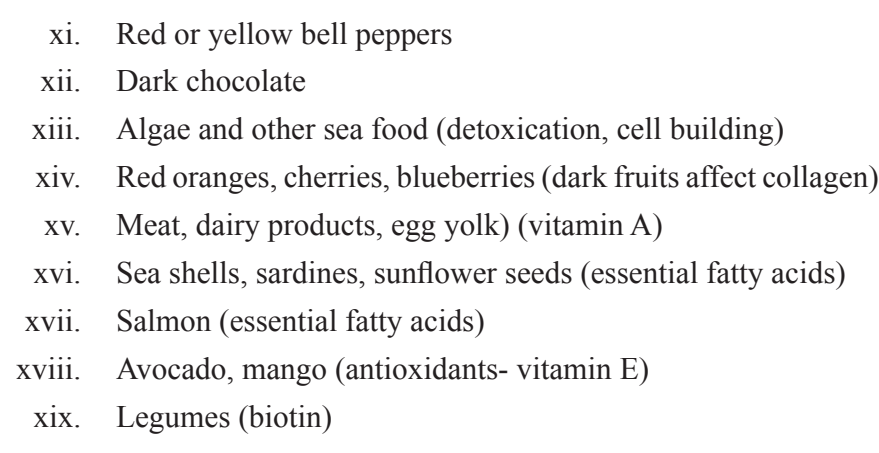

\section{Bad diet for skin}

a. Sugar (promotes inflammation risk and rapid skin aging)

b. Spicy hot food (promotes face redness with obvious capillary)

c. Caffeine (possible dehydration, but also anti-inflammatory effect)

d. Chocolate and fatty foods (sugar and saturated trans fats)

e. Alcohol (excessive drinking - free radicals, diuretic)

f. Processed foods (lack of micronutrients and excess of preservatives - emulators, colors, taste enhancers, aromas)

g. Fatty and fast foods and hydrogenised oils (lack of vitamins and minerals, high level of preservatives)

h. Salt (water retention, bloating)

i. Starch (white flour products)

Stress can also have a negative impact on skin; higher oil production can block and inflame skin pores, what is the base for bacteria development. Inflammation can be promoted due to high cortisol exposure. Smoking destroys skin. Only 5 cigarettes a day deprive cells of the necessary oxygen, while one cigarette lowers vitamin $\mathrm{C}$ for $25 \mathrm{mg}$. Women smokers need double vitamin $\mathrm{C}$ dose in comparison to non-smokers.

\section{Skin types and skin care}

Depending on how oily the skin is, how serious the water retention is, as well as on skin sensitivity, there are 5 basic skin types. Although it mainly has to do with genetics, some other factors influence skin characteristics, for example: hormones, birth control pills, as well as diet. ${ }^{19}$

\section{Basic skin types}

i. Normal skin (smooth, consistent complexion, without obvious lipid traces, does not demand special care)

ii. Oily skin (the entire face). Causes: malnutrition, hereditary factors, hormones, stress, wrong care

iii. Dry skin (not enough sebum or moisture. Causes: genetics, weather conditions, inappropriate care and hygiene)

iv. Mixed skin (fat in certain areas)

v. Sensitive skin (easily irritated, prone to redness and inflammation).

\section{Appropriate care}

a. Normal skin: regular hydration and avoidance of fatty products b. Oily skin: with right hygiene and application of adequate local products for skin care, attention should be paid to diet: avoidance of carbohydrates and sweets)

c. Dry skin: with appropriate care diet rich in essential fatty acids is recommended (Diet that makes your skin shiny), vitamins A, D, E, zinc. ${ }^{20}$ Avoid dehydrating foods (coffee, fizzy drinks) and foods that are digested slowly (fried and smoked meats, processed meats)

d. Mixed skin is most widely spread and demands special care

e. Sensitive skin: determine the cause of sensitivity and try to treat it.

\section{Discussion}

It is necessary to pay attention to skin health in order to realize its numerous functions that as an organ of human system it is processed. Skin is the barrier to the environment ( it protects the body against mechanical stimuli, various negative substances, microorganisms, radiation), it is important for maintaining homeostasis (it regulates the loss of liquids and body temperature), it has an important in the immune system and pain and temperature sensations, its appearance is important for the psychological state. It is of crutial importance to protect skin from negative factors like ultraviolet radiation, various chemicals, tobacco smoke, infections, as well as make available all the necessary nutrients in the diet, and appropriate care. In order to provide for normal functioning of the skin it is necessary to incorporate various foods of animal or plant origin, ${ }^{18}$ which contain vitamins, minerals, proteins, essential fatty acids, ${ }^{5-17}$ taking in consideration the type skin as well.

\section{Conclusion}

It is clear why full attention should be paid to skin, its health, functions and appearance. That is the reason why all the relevant facts should be known. Adequate diet is of crucial importance, with appropriate use of vitamins, minerals, proteins and other nutrients paying attention to possible beneficial and also harmful effects of certain foods, adjusted to the skin type. Adequate diet not only enables proper functioning, but also offers possibility of better communication and self image. We should be making effort to have healthy and beautiful skin. "When combined with a good diet, right dietary supplements can help keep your skin not only appear healthy, but also years younger". This should be applied in everyday practice in working with patients.

\section{Acknowledgments}

None.

\section{Conflicts of interest}

Author declares that there is no conflicts of interest.

Karadaglić $Đ$. Dermatologija u medicini. In: Karadaglić Đ, edit. Dermatologja. Beograd. 2016:3-5.

1. Madison KC. Barrier function of the skin:"la raison d,etre" of the epidemis. J Invest dermatol. 2003;121(2):231-241.

2. Bauman L. Skin ageing and its treatment. JPathol.2007;211(2):241-251. 
3. Farage MA, Miller KW, Elsner P, et al. Intrinsic and extrinsic factors in skin ageing: a review. Int J Cosmet Sci. 2008;30(2):87-95.

4. Zussman J, Ahdount J, Kim J. Vitamins and photoaging. Do scientic data support their use? J Am Acad Dermatol. 2010;63(3):507-525.

5. Rhie G, Shin MH, Seo JY, et al. Aging-and photoadung-dependent changes of enzymis and nonenzymic antioxidants in the epidermis and dermis of human skin in vivo. JInvest Dermatol. 2001;117(5):1212-1217.

6. Chen $\mathrm{L}, \mathrm{Hu} J Y$, Wang SQ. The role of antioxidants in photoprotection: A critical review. J Am Acad Dermatol. 2012;67(5):1013-1024.

7. Poljšak B, Dahmane R, Godic A. Skin and antioxidants. Journal of Cosmetic and Laser Therapy. 2013;15(2):107-113.

8. Schwartz E. La Vitamine C. Monographie Universite du Quebec a Chicoutimi DESS de Cosmetologgie 2016.

9. Burke EK. Interaction of vitamins $\mathrm{C}$ and $\mathrm{E}$ as better cosmeceuticals. Dermatol Ther. 2007;20(5):314-321.

10. Thiele J, Dreher F, Packer L. Antioxidant defense systems in skin. In: Elsner P, Maibach H, editors. Cosmeceuticals. New York: Marcel Dekker; 2000:145-187.

11. Thielle JJ, Schroeter C, Hsieh SN, et al. The antioxidant network of the stratum corneum. Curr Probl Dermatol. 2001;29:26-42.
12. Biewenga GP, Haenen GR, Bast A. The pharmacology of the antioxidant lipoic acid. Gen Pharmacol. 1997;29(3):315-331.

13. Trommer H, Neubert RH. Screening for new antioxidative compounds for topical administration using skin lipid model system. J Pharm Pharm Sci. 2005;8(3):494-506.

14. Szyszkowska B, Lepecka-Klusek C, Koztowicz K, et al. The influence of selected ingredients of dietary supplements on skin condition. Postep Derm Alergol. 2014;31(3):174-181.

15. Pietruszka B, Brzozowska A. Uwarunkowania suplementacji diety vitaminami i skladnikami mineralnymi w Polsce (Polish). Žyw Czlow Metab. 2002;29:215-219.

16. Proksch E, Feingold KR, Elias PM. Epidermal HMG CoA reductase activity in essential fatty acid deficiency: barrier requirement rather than eicosanoid generation regulate cholestErol synthesis. J Invest Dermatol. 1992;99(2):216-220.

17. Song XZ, Bi ZG, Xu AE. Green tea polyphenol epigallocatechin-3gallate inhibits the expression of nitric oxide synthase and generation of nitric oxide induced by ultraviolet B in HaCaT cells. Chin Med J (Engl). 2006;119(4):282-287.

18. https://minutzamene.com/5-tipova-kože-lica/

19. http://nadijeti.com/2010/08suva-koža-i-ishrana//22/ 